Memorias del VII Encuentro Nacional de Experiencias en la Enseñanza de la Biología y la Educación Ambiental y II Congreso Nacional de Investigación en la Enseñanza de la Biología

\title{
NARRATIVAS DE JOVENES TRAPECISTAS SOBRE SU MUNDO DE LA VIDA COMO UNA ORIENTACIÓN DIDÁCTICA PARA LA ENSEÑANZA DEL CONCEPTO VIDA DESDE LA BIOLOGIA.
}

\section{NARRATIVES OF YOUNG PEOPLE ABOUT THEIR LIFE'S WORLD AS A DIDACTIC GUIDANCE FOR THE TEACHING OF LIFE'S CONCEPT FROM THE BIOLOGY.}

\section{Susam Paola Laverde Sánchez ${ }^{1}$}

\section{Resumen}

Hablar de la vida y lo vivo en el contexto contemporáneo denota un panorama complejo. Enseñar la vida y lo vivo desde la biología, sugiere ampliar los límites globales que establecen unas metas educativas, en cumplimiento a un currículo orientado a través de unos estándares educativos planteados de manera homogenizante. Sin demeritar dichos fines educativos, es primordial entender que la vida y lo vivo se aprende y se vivencia en contexto; que somos seres vivos, biológicos y humanos supeditados a nuestras maneras de comprender la vida misma; y el porqué es esencial reconocerla y narrarla, más aún cuando deseamos que nuestra práctica docente incida en la vida de otros y otras, en su transformación individual y colectiva.

Es así que, para este proceso investigativo cambia el propósito educativo: se aborda la vida y lo vivo desde el contexto propio y la experiencia de vida donde, a través de la narrativa como una metodología de investigación cualitativa, se reconocen, leen, transcriben y construyen las comprensiones y expresiones de 50 jóvenes en situación de vulnerabilidad, que hacen parte del Instituto para la Protección de la Niñez y la Juventud (IDIPRON), sede UPI santa Lucia, ubicada en la ciudad de Bogotá, Colombia. Con el ánimo de que estas narrativas se constituyan en una orientación didáctica para la enseñanza del concepto vida, desde la biología en contexto.

Es una propuesta alterna a las maneras tradicionales de abordar la vida y lo vivo desde la enseñanza de la biología, en vista de los múltiples contextos de trabajo donde vivenciamos la labor docente, prácticas que deben trascender.

\footnotetext{
${ }^{1}$ Especialista En Enseñanza De La Biología. Licenciada En Biología , Universidad Pedagógica Nacional
} 
Bio-grafía Escritos sobre la Biologia y su Enseñanza.

Edición Extra-Ordinaria. ISSN 2027-1034 P. p368 - 386

Memorias del VII Encuentro Nacional de Experiencias en la Enseñanza de la

Biología y la Educación Ambiental y II Congreso Nacional de Investigación en la

Enseñanza de la Biología

\section{Abstract}

Talking about the life and something live in the contemporary context denotes a complex picture. Teaching the life and something live from biology, suggests expanding global limits which establish an educational aims, complying an oriented curriculum through educational standards raised uniformly. Without discrediting these educational purposes, it is essential to understand that the life and something live is learning and living in context, that we are living, biological and humans subject to our ways of understanding the life itself, and why is essential knowing and narrate it, especially when we want our teaching practice affects the lives of others, in their individual and collective transformation.

That's why, for this investigative process changes the educational purpose: the life and something live are approached from the particular context and life experience where, through the narrative as a qualitative research methodology, it is recognized, read, transcribed and It build knowledge and expressions of 50 vulnerable young people, who are part of the Institute for the Protection of Children and Youth (IDIPRON) Upi Santa Lucia located in the city of Bogotá, Colombia. With the hope that these narratives constitute didactic guidance for the teaching of life's concept from the biology.

It is an alternative proposal to the traditional ways of approaching the life and something live from teaching biology in view of the multiple contexts of work where we experience the teaching practices that should transcend.

Palabras Clave: Vida, vivo, narrativa, jóvenes, experienciar, mundo de la vida, Enseñanza De La Biología, Biofilia.

Key Words: Life, something live, narrative, young people, experiencing, life world, teaching biology, biophilia.

\section{Introducción}

Surge este ejercicio investigativo ${ }^{2}$ en el Instituto para la Protección de la Niñez y la Juventud (IDIPRON), UPI Santa Lucía, ubicada en la ciudad de Bogotá;

\footnotetext{
${ }^{2}$ Proyecto de grado realizado entre los años 2012 y 2013 para optar al título de Especialista en Enseñanza de la Biología, Universidad Pedagógica Nacional. Como asesores del proyecto estuvieron los docentes Cesar Augusto Delgado y Norma Constanza Castaño, del Departamento de Biología de la Universidad Pedagógica Nacional.
} 
Memorias del VII Encuentro Nacional de Experiencias en la Enseñanza de la Biología y la Educación Ambiental y II Congreso Nacional de Investigación en la Enseñanza de la Biología

trabajando con jóvenes del sexo masculino, en edades entre los 14 y 26 años, llamados trapecistas por estar continuamente en situaciones de riesgo y vulnerabilidad social. Desde la enseñanza de la biología, en la diaria convivencia, y tratando de comprender sus situaciones de vida, se evidencia que para la mayoría de ellos, sus vidas se resumen en cualquier oportunidad, cualquier situación que se viva, en un sin sentido, y en vivir la vida como venga. A su vez, se muestran pocos sentidos o expectativas de vida, ya que la vida misma que les ha tocado ha sido dura, para guerrearla, escasa, violenta, estigmatizada o sin esperanza.

De esta manera, las expresiones de los jóvenes trapecistas sobre la vida me llevaron a pensarme dentro de la labor que diariamente asumo como docente; que tanta trascendencia tiene para ellos la construcción de conocimientos en el aula, aplicados a la cotidianidad; y en los vínculos grupales, afectivos y colectivos surgidos en este proceso diario de enseñanza y aprendizaje, a partir de la biología como estudio de la vida y lo vivo. Sentí entonces la necesidad de reconocer las comprensiones sobre la vida y lo vivo de 50 jóvenes trapecistas, desde sus propios contextos, experiencias y mundos de vida. Diferentes comprensiones de vida y vivo a las que comúnmente se esperan al enseñar biología. Ya que el interés por la pregunta ¿Qué es la vida?, como plantea (Diéguez, A. 2012), en el capitulo "La búsqueda de una definición de vida", del libro "La vida bajo Escrutinio" nació de las investigaciones sobre la vida artificial, mas no como tema que apasionara u ocupara a los biólogos, ya que consideraban innecesario saber que era en sí. De allí, los científicos buscan la definición de vida. Los filósofos que luchan con las grandes preguntas de la vida ya no están solos. Ahora los científicos luchan también por definir la vida ya que la manipulan, la buscan en otros planetas o incluso la crean en tubos de ensayo.

O como afirma Orlando Vargas en su texto "La noción de la vida en la biología contemporánea" del I semestre de 2001, de la Cátedra Manuel Ancizar, Ética y Bioética: la pregunta "qué es la vida" ha sido un rompecabezas para biólogos, físicos, teólogos y poetas. Es uno de los problemas científicos y filosóficos por excelencia y a los cuales, en la mayoría de los casos, se unen las concepciones religiosas en la búsqueda de una visión del universo, una visión del mundo y una visión del hombre. De la forma como el hombre ha respondido a esta pregunta, construye su forma de sentir y de entender la vida (de respetarla o degradarla, de exaltarla o de humillarla. pág. 241). Puede entonces que no haya más remedio que asumir el dictum nietzscheano de que lo que tiene historia no puede tener definición, y la vida, si por algo se caracteriza, es por haber tenido historia; una historia que no se deja atrapar por fronteras precisas. (Diéguez, pág. 42).

Es así que las comprensiones sobre la vida y lo vivo en los jóvenes trapecistas se construyeron a partir de la narrativa como enfoque de interpretación de la realidad 
Memorias del VII Encuentro Nacional de Experiencias en la Enseñanza de la Biologia y la Educación Ambiental y 11 Congreso Nacional de Investigación en la Enseñanza de la Biología

y como método de investigación educativa (Rivas Flores y David Herrera Pastor, 2009). Ya que como expone el filosofo Paul Ricoeur en el capítulo 3 del libro "La educación como acontecimiento ético. Natalidad, narración y hospitalidad (2000): "La comprensión de sí es narrativa de un extremo a otro. Comprenderse es apropiarse de la propia vida de uno. Ahora bien, comprender esta historia es hacer el relato de ella, conducidos por los relatos, tanto históricos como ficticios, que hemos comprendido y amado. Así nos hacemos lectores de nuestra propia vida".

Narrativas sobre la vida y lo vivo, construidas desde sus propios relatos escritos y orales, con la expectativa de asumirse diferentes, sintiéndose ellos mismos como seres vivos, biológicos y sociales. Para reconocerse como un ser vivo que hace parte del planeta tierra, cuya evolución como especie animal, dentro de la temporalidad de su historia natural, lo hizo un ser social: pensante, hábil, humano, constructor de símbolos, sentidos y lenguajes. Pero también, poseedor de identidad, de vivencias, de experiencias, de maneras de vivir, que no solo se comprenden desde un texto escolar, un estándar a cumplir o una evaluación que hacer. Un narrador de la vida, de lo vivo y del experienciar de mundo, un sujeto que se pregunta sobre sí mismo y sobre sí mismo como otro. Habitantes de un mismo planeta, dueños de vidas diversas, únicas; habitantes originados de una misma evolución biológica y vital. Es esta la raíz de la comprensión de sí mismo. Es esta la comprensión del mundo, de la intersubjetividad y del como, por qué y para que habitan en él. Es este el comienzo de algo nuevo. Una nueva manera de verse habitando el mundo como ser vivo.

Se articularon entonces aportes teóricos, epistemológicos y metodológicos desde la reflexión educativa y la acción filosófica, a partir de los planteamientos del filosofo Paul Ricoeur, que sugieren una identidad narrativa, ya que nos educamos en un mundo que nos es narrado, y desde el cual, a través de la ficción y la imaginación, nos constituimos desde nuestro ser animal, para buscar y encontrar algún sentido a nuestra vida. Desde allí, también parte la imaginación creadora y narrativa que permite a los sujetos narrar sus acciones, su proceso activo de representarse desde su propia temporalidad, verse en sí mismo y responder al ¿quién soy?, consolidando su identidad narrativa. Se reconoce entonces, la relación entre la representación de la acción de la praxis, a través de la triple mimesis como apuesta creadora que permite prefigurar, configurar y reconfigurar la acción, desde el texto narrado y las posibles incidencias del mismo en las maneras de comprender y transformar la vida, lo vivo y el experienciar de vida desde los propios sujetos. Y más cuando los sujetos tenemos la posibilidad de reconocer que, gracias a la manera como nos hemos relacionado biológica y psicológicamente con otros seres vivos, fue que nos constituimos como la especie que somos, con las características afectivas e intelectuales que hoy tenemos, planteamiento hecho por Pablo Páramo (1999), en su libro "Nuestros vínculos con los animales (Pág. 5). Y principalmente que dependemos de la relación que 
Memorias del VII Encuentro Nacional de Experiencias en la Enseñanza de la Biología y la Educación Ambiental y II Congreso Nacional de Investigación en la

\section{Enseñanza de la Biología}

cotidianamente establecemos como seres vivos con la vida, ya que a través de ella nos reconocemos como una especie biológica y social. Este planteamiento, se equipara con la hipótesis de la biofilia propuesta por Wilson (1984), Kellert y Wilson (1993) y Kellert (1997), según la cual: ...existe una tendencia de carácter biológico en el ser humano para relacionarnos con la vida y los procesos naturales, tendencia que es integral al proceso de desarrollo de la especie humana y esencial para su crecimiento físico y mental. (pág. 19). Lo que permite sostener que esta inclinación a afiliarnos con la vida y los procesos de vida (funciones ecológicas y estructuras) tiene una raíz biológica, hace parte del legado evolutivo de la especie, está asociada con las ventajas competitivas y el ajuste genético, aumenta las posibilidades para lograr un significado para el individuo y una realización personal, y finalmente una base para una ética sobre el cuidado y conservación de la naturaleza, más específicamente de la diversidad de la vida (pág. 19).

Es entonces allí que las narrativas construidas a partir de los relatos escritos y orales de los jóvenes trapecistas pretendieron constituirse como una orientación didáctica para la enseñanza del concepto vida desde la biología, comprensiones alternas a los dictamines tradicionales y estandarizados que se esperan cumplir al interior de la labor educativa. Narrativas mediadas por la emoción, la razón, el mundo de la vida, y las interacciones cotidianas que surgen consigo mismos como animales humanos; con el planeta que habitan como seres vivos en interacción biológica, evolutiva y ambiental con otros seres vivos; y como sujetos colectivos que pueden trascender.

\section{Metodología}

Basada en la perspectiva metodológica constructivista (cualitativa), donde se combinaron tres referentes metodológicos: la narrativa, la hermenéutica y la fenomenología. Introduciendo la triple concepción de la mimesis del filosofo francés Paul Ricoeur, o de los tres niveles de imaginación creadora (prefiguración, configuración, y reconfiguración) como la herramienta esencial para construir y comprender las narrativas de vida y vivo desde el experienciar y mundos de vida de los jóvenes trapecistas.

Inicialmente, se identificaron las características poblaciones y contextos propios de los jóvenes trapecistas. Luego, se generaron estrategias de recolección de datos tanto escritas (tarjetas que los inducían a expresarse sobre los términos vida y vivo); audiovisuales (socialización de videos musicales de 14 grupos de rap sobre la vida, lo vivo y la experiencia; socialización de 37 imágenes alusivas a la vida, 37 imágenes alusivas a lo vivo y 28 imágenes alusivas a la biofilia); y orales (grabación de las voces de los jóvenes). Dichas estrategias de recolección de datos orientaron y apoyaron las preguntas: ¿Qué es la vida?, ¿Qué es lo vivo, ser 
Memorias del VII Encuentro Nacional de Experiencias en la Enseñanza de la Biología y la Educación Ambiental y II Congreso Nacional de Investigación en la Enseñanza de la Biología

vivo?, ¿Cómo ha sido su experiencia de vida?, realizadas a los jóvenes. Posterior a la recolección de datos, se leyeron y transcribieron las expresiones tanto escritas como orales de los jóvenes sobre la vida, lo vivo y su experienciar de mundo como sujetos. Con el conjunto de transcripciones realizadas se construyeron tres narrativas generales basadas en la triple mimesis o imaginación creadora, las cuales se alimentaron de otras narrativas especificas cargadas de sentidos y significados.

\section{Resultados Y Discusión: "De La Vida Y Lo Vivo En La Biología Hacia Los Relatos Y Las Narrativas De Los Jóvenes Como Sentidos Y Comprensiones De Sus Mundos De Vida".}

Como se expuso en el apartado anterior se construyeron tres narrativas generales basadas en la triple mimesis o imaginación creadora, desde la prefiguración, la configuración y la reconfiguración; narrativas alimentadas de otras narrativas especificas. Se resaltan los relatos escritos y orales de los jóvenes, como sigue a continuación:

\section{Narrativa 1: La Comprensión Previa De La Vida, Lo Vivo Y Del Mundo De La Vida, En Los Jóvenes Trapecistas: La Prefiguración.}

De su vida familiar, de su vida en la calle, en el barrio, con los socios, y en las instituciones educativas que han atravesado, se evidencia una ruptura permanente con lo instituido, siendo la familia, el colegio y la institucionalidad, sistemas en donde la vida se les vuelve un problema mayor. Ya que la familia, en pocos casos, les ha aportado afecto, encuentro, satisfacción; la institución, se denota como todas aquellas normas sociales que rechazan continuamente y como viven la permanente exclusión social, el desasosiego, la poca aceptación de quienes son; y el colegio, les genera desmotivación, pereza y aburrimiento, colegios e instituciones que, para la enseñanza, se limitan en la mayoría de los casos a cumplir con una serie de estándares descontextualizados, impositivos, dirigidos hacia la competitividad entre humanos.

De la familia: los jóvenes trapecistas se convierten en los moldes sobre los cuales se deben instaurar una serie de prácticas que les son inculcadas, de generación en generación, sin posibilidad de consenso y negociación, dialogo, o toma de decisión de lo que se quiere y no se quiere ser.

De la institucionalidad y la sociedad: es un continuo rechazo, el ir en contra de las normas sociales impuestas desde el propio sistema, un sistema capitalista y 
Memorias del VII Encuentro Nacional de Experiencias en la Enseñanza de la Biología y la Educación Ambiental y II Congreso Nacional de Investigación en la Enseñanza de la Biología

globalizante que construyó estratos de vida, estratos que solo han perpetuado la discriminación, exclusión y rechazo social.

De lo educativo: algunos jóvenes trapecistas incursionaron en el sistema educativo colombiano, y específicamente, en colegios distritales o institutos de validación, de donde la mayoría han desertado; e incluso, algunos de ellos no han pisado institución educativa alguna, ya que la calle se convirtió en la mejor escuela de la vida.

Desde allí cuestiono mi quehacer educativo como docente en biología, siendo que la educación, como acción ética y formadora de identidad permite contarnos, relatarnos y narrarnos a nosotros mismos; contarnos para vernos reflejados, pensarnos y transformar. Entonces: ¿Qué significativo ha sido para los jóvenes trapecistas el aprender la vida y lo vivo desde la biología como ciencia? ¿Son sus mundos de vida las bases primarias para pensarse y reflexionarse como seres vivos y actuar en consecuencia con su propia vida? ¿Es la educación en ciencias y lo que se espera del saber y el saber hacer, sin ser, la base primordial para comprender eso que llamamos vida y mundos de vida.

\section{NARRATIVA 2: LAS NARRATIVAS DE LA VIDA, DE LO VIVO Y DEL MUNDO DE LA VIDA DE LOS JÓVENES TRAPECISTAS: LA CONFIGURACIÓN.}

Hoy, jóvenes trapecistas, me tomo la tarea de configurarlos, a ustedes y a sus mundos de vida, en la escritura de este texto. Un texto que proviene de la prefiguración de sus propias vidas, de cómo las percibo, las he escuchado, las siento... hoy, parto de la imaginación, de prefigurar mundos posibles e ideales, donde nada debería ser imposible... hoy, configuro sus expresiones escritas, sus relatos orales, a través de la narrativa de sus sentires, acciones y realidades hechas texto. A través de mi propia comprensión como docente en biología, especialista en la enseñanza de la biología y persona que también posee un propio mundo, mi mundo de la vida.

\section{Lo que es la vida para los jóvenes trapecistas:}

- La vida y los seres vivos: los jóvenes perciben que la vida es propia no solo de los humanos, sino también de las plantas y otros animales que constituyen al planeta tierra, el cual requiere de condiciones como el aire para mantener vivos a los seres vivos. El movimiento es otro de los aspectos fundamentales de los seres vivos, en los cuales se denotan las características biológicas básicas que los definen: nacer, crecer, reproducirse y morir: "Para mí la vida es todo ser humano... Es la parte del factor primario para que de vida a un ser, un organismo, planta o ser vivo... Yo pienso que el aire nos da vida 
Memorias del VII Encuentro Nacional de Experiencias en la Enseñanza de la

Biología y la Educación Ambiental y II Congreso Nacional de Investigación en la

\section{Enseñanza de la Biología}

porque el aire nos ayuda a limpiar el ambiente y así no recibimos tantas bacterias y otras bacterias que hayan en el aire... Un pájaro que tiene vida".

Se establece una conexión y afiliación con la vida y con los demás seres vivos, cuya raíz biológica permite aumentar las posibilidades de que el sujeto humano logre un significado de la vida y su realización personal: "La vida es toda forma de poder hacer muchas cosas y la vida es parte de muchos animales terrestres, acuáticos, aéreos y todos necesitamos de ella para que los animales puedan atrapar su comida y nosotros los seres humanos poder trabajar". Allí la biofilia entra a jugar un papel esencial en los relatos escritos y orales de los jóvenes trapecistas ya que, si desde la enseñanza de la biología y más específicamente de la vida, se reconoce esta filiación con la vida y los demás seres vivos, es muy probable que no se limite, desde las instituciones educativas, a transmitir un conjunto de características biológicas que comparten los seres vivos, como se pretende desde su enseñanza: "Por la vida yo entiendo que es algo que se mueve, por ejemplo una flor tiene vida, nace, crece, se reproduce y muere...Yo soy vida como otra gente que es humana y animales. Todo lo que se mueve en la tierra y respira".

- La vida y la creación: perciben a Dios como el ser supremo que les dio la oportunidad de venir a este mundo y vivir, de existir, de acuerdo a las oportunidades que la misma vida les ha brindado, sus decisiones, y sus acciones: "Vida fue la que mi Dios nos dio a todos nosotros y por eso estamos aquí.... Algo muy bonito que dios le brinda a todo ser humano, la libertad, el amor, la paz. Además es algo muy grande y bello que nos ha dado dios... Es algo maravilloso que diosito nos brindo para poder caminar, hablar, sentir, amar... y si uno va a una iglesia también, con mi dios".

- La vida y las maneras de vivir: deciden sus caminos y viven la vida como consideran que es mejor vivirla: "Cada uno tiene su forma de vivir... También puede ser la forma de vida que llevamos, como vicios y más pasos que nos conllevan a un mal futuro... La vida es para mí la vida que uno vive y vivirá para toda la vida y poderla vivir como la quiera uno... Es estar bien, hacer un proyecto y mantenerse con buena salud".

- La vida como oportunidad: acogen la vida como el espacio - tiempo, para poder disfrutar, vivir y aprovechar al máximo las oportunidades que esta les brinda: "Es aquella palabra que habla por sí misma... La vida es para mí todo porque uno sin vida que hace, nada... La vida es muy hermosa para mí gracias a las oportunidades que me brinda...la vida es como un don, un regalo". Aquí, su historicicidad, su temporalidad, su pasado, presente y futuro se congregan al asumir el todo de la vida, como la oportunidad en la que pueden ser o no ser, sentir, hacer y el saber para que vivir. 
Memorias del VII Encuentro Nacional de Experiencias en la Enseñanza de la

Biología y la Educación Ambiental y II Congreso Nacional de Investigación en la Enseñanza de la Biología

- La vida como disfrute y posibilidad: la vida es vista como la posibilidad de trazarse una meta, venciendo los obstáculos para alcanzarla: "Salud, comer bañarse, tomar, hablar, soñar... Es para disfrutar muchas cosas, humildes cosa... La vida para mí significa trazar una meta, trazar un camino, un sendero que uno mismo se traza para poder alcanzar esa meta, y vencer obstáculos que nos puedan llevar a la cima, y poder sobrevivir, y enfrentar ese mismo destino que nos trazamos, poderlo llevar más alto para poder ser mejores personas cada día, eso es la vida". Alí, es esencial el reconocimiento propio, las maneras de sentirse, verse, pensarse y apropiarse de su propia vida, para cuestionarla, mejorarla o transformarla, en pro de asumirse como sujeto que vive, goza, disfruta, tiene posibilidades de ser lo que quiere ser: "La vida es pensar, ser feliz, caminar, el poder respirar, y tener inspiraciones como persona...La vida es algo muy especial para los seres humanos, porque si no tenemos vida no disfrutamos de todas las cosas del mundo".

- La vida en sí mismo y en sí mismo como otro: Los jóvenes trapecistas establecen una relación profunda con el otro, desde sí mismo, con su familia, sus amigos, los que le rodean, configurando vínculos sociales, desde su identidad personal, el dialogo, la convivencia y el compartir con los demás: "Saber salir adelante con su familia, que lo lleven bien, de corazón a corazón. Para eso vive uno. Y con amigos que lo quieren, que no lo dejan tirado a uno en la calle, que lo lleven vacano las personas a uno". A su vez, es poder pensar, razonar, tener inteligencia y entendimiento de sus mundos de vida, pero solo desde el reconocimiento e identidad propia: "La vida es la forma como uno convive con las demás personas, comparte, dialoga y se identifica...La vida es para sentirla, acariciarla, no perder momentos buenos con la familia, es una cosa que solo nos entregan una vez y saber que camino escoger y aprovechar las cosas que uno vive diariamente con los que comparte las cosas, y si uno pues no sabe aprovechar las cosas que tiene desde pequeño, a más tardar termina como los fulanos de los videos que vimos, consumidos ya".

\section{Lo que es lo vivo para los jóvenes trapecistas:}

- Lo vivo en relación con la vida, los seres vivos y el planeta tierra: reconocen que lo vivo permite darle sentido al mundo de la vida, ya que, se evidencia de manera contundente la estrecha relación evolutiva y biológica que como seres vivos, llamados humanos, tenemos con otros seres vivos que también habitan este planeta tierra. Donde dependemos unos de otros, donde se establecen vínculos entre la vida y lo vivo, que son los únicos que permitirían entender el sentido de estar vivo, de vivir. A través de la enseñanza de la vida desde la biofilia como la tendencia innata para centrarnos en la vida y en los procesos relacionados con la vida: "Las plantas, los animales, los humanos, el planeta...Son todos los seres existentes en la tierra que nacemos, nos 
Memorias del VII Encuentro Nacional de Experiencias en la Enseñanza de la

Biología y la Educación Ambiental y II Congreso Nacional de Investigación en la

\section{Enseñanza de la Biología}

reproducimos y por ultimo morimos... Los tres seres vivos existentes en la tierra son las plantas, los animales y los seres humanos...Es un sobreviviente, mi mamá, mis hermanos, los del patio y los animales...Es algo o alguien que siente, se alimenta, se reproduce y está vivo... Yo pienso que vivo es cuando una planta se encuentra en su posición que nadie la puede cortar ni dañar". A su vez, es interesante ver como en tres palabras "nacemos, nos reproducimos y morimos", se define lo vivo, como características básicas que compartimos entre todos: "Es lo que nace, crece, se reproduce, y hace darle sentido al mundo, si no hubiera vida todo seria muerto, todo seria desértico, y los maderos serian secos, no habrían cuerpos vivientes, ni gente que sembrara y segara, no hubiera economía, no hubiera sentido en este mundo si no hubiera vida... Son los perros, los gatos, los moscos, porque están vivos...y nosotros también, los arboles que tienen vida, la hierba, eso le da vida a uno"... risas.

Lo vivo en relación con los humanos: ven los humanos, con vida y mente propia para pensar, para decidir, para construir conocimiento, reflexionar, cambiar, asumir una responsabilidad, proyectarse, ser: "Vivo es un ser que tiene vida propia y mente propia como por ejemplo un humano a diferencia de otras cosas que se mueven tras una vida artificial como los robots, los autos, etc.... Somos nosotros los humanos como siendo vivos en todas las cosas $y$ experimentar". Las acciones humanas que los jóvenes trapecistas exponen, como pensar, experimentar, tener inteligencia y conciencia son esenciales en cuanto somos seres humanos que reconocemos una historicicidad y una memoria evolutiva y biológica que nos permitió crear un constructo social humano. De lo contrario, pasamos a ser un símbolo del desconocimiento propio, del otro y del mundo; seres humanos deshumanos, vacios, intolerantes y miserables que se ahogan en el individualismo, la intolerancia, la estigmatización hacia otros, el rechazo y la segregación de otros que vemos diferentes, marcando las desigualdades sociales tan relucientes en este mundo contemporáneo: "Es lo que uno tiene para moverse, para tener conciencia...Vivo es tener los cinco sentidos, poder moverse, pensar, sentir... Un ser vivo es un sujeto $u$ objeto que tiene vida propia y la capacidad de tener movimiento e inteligencia".

- Lo vivo en relación con la experiencia de vida: estar vivo es aprovechar la vida, dejar huella en este mundo, vivir. En otros momentos, es ser más vivo que otros, para sí mismo, en sus acciones y decisiones, tomar más riesgos y vivir más experiencias; o por el contrario, limitarse a vivir el día a día como venga, en un mundo donde no se avanza ni se progresa: "Lo vivo es lo que uno hace. Una experiencia como la quiera uno... Es el que es más vivo que alguien sin ser más que los demás y estar atento en las cosas de la vida y cada vez que nos tropezamos levantarnos y seguir...Vivo es un mundo de malos hábitos y costumbres diversas en un mundo de no progreso...Fumar...Rap vivo...No 
Memorias del VII Encuentro Nacional de Experiencias en la Enseñanza de la

Biología y la Educación Ambiental y II Congreso Nacional de Investigación en la

\section{Enseñanza de la Biología}

pensar que a uno lo vayan a matar, que respeten a las personas". Dentro del mundo de la vida, es gozar la experiencia de estar vivo y aprovechar la oportunidad de vivir, sentir, y sobre todo resistir, caer y levantarse ante las dificultades y adversidades que el propio mundo y la sociedad impone. Ya que lo único sin solución es la muerte: "Lo vivo es vivir, es conocer, es sentir, es gozar cada momento de la vida...estar vivo es aprovechar la vida a cada minuto, a cada segundo que pasa, cada problema, cada solución, cada cosa tiene su lado bueno y su lado malo, la vida tiene su lado bueno y su lado malo y lo único que no hay solución es la muerte, ya uno se acuesta y duerme completo, y ahí si no hay vida y no hay nada... Estar vivo para mi es aprovechar la vida y el aprovechar la vida sería como gozar cada cosa, lo malo, lo bueno, no irnos de este mundo sin dejar la huella, que vivió, entonces que estuvo ahí y dejó su raya... Estamos acá porque nos tocó".

- Lo vivo y la creación: se denota lo vivo como la representación de las cosas hermosas que hay en el mundo, creadas y puestas en el mismo por un Dios, quien nos otorgó un propósito para estar en este mundo de la vida. Vuelve entonces a resurgir el tema de la vida y lo vivo desde la mano creadora de un dios, en relación a todo lo que existe y los rodea: "Pues para mí lo vivo son las cosas hermosas profe que hay en la vida, los paraísos, los arboles, los animales, las personas... todas las personas tenemos una vida que gracias a dios nos ha dado y lo vivo para mi es saber vivir la vida con... que hay que consagrar el mandamiento que nos dio dios que fue la vida... es hermosa vivirla, es hermoso".

\section{- La experiencia de vida y el mundo de vida de los jóvenes trapecistas como sujetos:}

* JOVEN 1: ¿Buena o mala?...INVESTIGADORA: como haya sido para ti, eso solo lo sabes tú... JOVEN: "pues hasta el momento como siempre le he agradecido a mi dios Jehová por la vida que me ha dado; sin embargo, me han faltado muchas oportunidades, como he visto personas que tienen muchas cosas y las desperdician. Como por ejemplo he visto personas que están en la calle porque quieren estar, porque las familias son pudientes y tienen formas de ser profesionales, de ser mejores personas y no aprovechan eso, y uno que no ha tenido esas oportunidades intenta aprovechar cada pedacito de oportunidad que le da la vida y muchas veces como que se le cierran las puertas, porque uno mismo hace que se le cierren, o porque no tiene las mismas oportunidades que tienen otras personas".

* JOVEN 2: Ha sido dura, la he guerreado, he conocido muchos lugares del programa, y he gozado cada momento y cada experiencia que he vivido dentro del mismo programa... he conocido muchos lugares fuera de Bogotá del mismo 
Memorias del VII Encuentro Nacional de Experiencias en la Enseñanza de la

Biología y la Educación Ambiental y II Congreso Nacional de Investigación en la

$$
\text { Enseñanza de la Biología }
$$

IDIPRON, ha sido una experiencia de vida...INVESTIGADORA: y cuando dices que tu experiencia de vida ha sido dura para ti, a que te refieres...J JOVEN: "a muchas cosas profe, porque usted tiene que vivir lo que es la calle, el consumo, ver la explotación, ve como usted tiene que correr de los mismos tombos para que no lo revienten a uno. Usted tiene que pararse y enfrentarse duro para que un tombo no lo coja a usted y le quite lo que usted se está ganando limpiamente, $y$ usted tiene que salir huyendo porque un tombo lo va a coger porque simplemente se "enamoró" de usted y va detrás suyo a simplemente agarrarlo porque si... es correr y es lo mismo ocultarse de uno mismo para sobrevivir, y la vida es eso, y eso es lo que a uno le toca hacer... mi experiencia de vida ha sido eso, lucharla, tanto dentro como fuera del programa".

* JOVEN 3: "Mi experiencia los últimos años, al principio fueron terribles, pasé por cosas feas, sentí que nadie me quería pero cuando estuve cerca a dios mi vida cambio completamente, estuve más tranquilo, sabía que tenía a mi familia, todos no me habían decepcionado, sabía que las cosas que dios da son hermosas, sabía que no me iba a faltar un plato de comida nunca, sabía que dios siempre me iba a colaborar cuando estuviera solo, aunque nunca estoy solo porque siempre estoy con él, él nunca desampara a nadie, el siempre está con nosotros, y saber gozar la vida.

Al principio cuando tenía el velo que se puso en mi, pues no sabía que era la vida, me sentía triste, tenía ganas de suicidarme a veces, no quería comer, no quería hacer nada, no quería jugar, no quería estar con nadie, quería estar solo, pero cuando conocí a dios supe que era distinto, que era lo contrario, nunca uno está solo, siempre está con alguien, está con la familia, está con los amigos, algunos amigos buenos, algunos amigos malos que dicen que lo malo es bueno y que lo bueno es malo, pero cuando sepan que tienen un velo encima, se van a arrepentir de todo lo que han hecho y todo lo que han dicho... eso es todo lo que tengo por decir profe".

\section{NARRATIVA 3: LA APROPIACIÓN DE LAS NARRATIVAS SOBRE LA VIDA, LO VIVO Y EL MUNDO DE LA VIDA EN LOS JÓVENES TRAPECISTAS: LA RECONFIGURACIÓN.}

.De la temporalidad del texto narrado a la apertura de otras formas de narrar la vida, lo vivo y el mundo de la vida, para significar su enseñanza desde la biología, en los jóvenes trapecistas:

Para que la enseñanza de la vida y lo vivo desde la biología como ciencia, represente un significado en los educandos se requiere enfatizar en la biofilia, como posibilidad biológica, evolutiva, psicológica, estética, intelectual, 
Memorias del VII Encuentro Nacional de Experiencias en la Enseñanza de la Biologia y la Educación Ambiental y 11 Congreso Nacional de Investigación en la Enseñanza de la Biología

cognoscitiva, espiritual. Es esta, la tendencia biológica para centrarnos en la vida y en los procesos relacionados con la vida la que nos permite comprender quienes somos como seres vivos, en un planeta tierra majestuoso que nos permitió ser. Ser una especie más entre millones de especies que habitamos este mundo. Sin ser más, sin ser menos, al fin de cuentas, dependemos de esta naturaleza, de miles de ecosistemas, elementos naturales, hábitats, puesto que sin ellos no accederíamos diariamente a nuestros alimentos, gustos y necesidades.

Dependemos de otros seres vivos, de este sistema vivo que nos soporta, nos sostiene y el cual, como docentes en la enseñanza de la biología, limitamos a los contenidos escolares de los textos, avalados por currículos construidos en base a los estándares exigidos, a nivel nacional. Lo paradójico de este tema es que los estándares, como es sabido, provienen de contextos sociales y educativos, diferentes a los contextos propios de las realidades colombianas. Realidades particulares, que difícilmente se pueden homogenizar y estandarizar. De allí que los estándares, como lineamientos educativos que preparan a los educandos frente a un saber y un saber hacer, deben desarticularse para adecuarse y acomodarse a las características propias de la población. Para este caso, con los jóvenes trapecistas se decide, desde este ejercicio educativo propio, revertir el sentido de la enseñanza de la vida desde la biología como ciencia, a la enseñanza de la vida y lo vivo en contexto como razón propia de estar, ser y vivir en el mundo, a partir de las narrativas de los mundos de vida de sí mismos. Sus relatos escritos y orales, configurados en acciones, reconfigurados en el acto que es leer la vida propia, se recrean al verse ellos mismos como seres vivos que mantienen y comparten características biológicas con otros seres vivos como son el nacer, crecer, reproducirse y morir. El sentir, el moverse, el habitar el mismo mundo, el mismo planeta tierra, al mismo tiempo que otros seres vivos que poseen esa misma vida, representada en sus rasgos físicos, fisiológicos, estructurantes, metabólicos, entre otros.

La vida, representada en mil y una definiciones, que van desde un dios que la creó, un dios que les dio la posibilidad de vivir, de experimentar, de no desaprovechar la experiencia de vida y vivirla plenamente, decidiendo el camino de su vida propia. Desde un dios paralelo a la evolución animal e histórica, espacio temporal, que plantea la biología como ciencia, donde la vida y el interés por estudiarla, renació cuando se hablo de la vida artificial, la vida en otros planetas y la vida originada en laboratorio. Definiciones que divergen en sus planteamientos, que han sido la base de ideologías, descubrimientos, pensamientos, sentires, mundos de vivir y ser. Ya que desde la ciencia, la biología, la filosofía, la biofilia y el mundo de la vida, se deben forjar elementos convergentes que la ayuden a definir, para diferentes propósitos, ya que de una sola manera no se puede hacer; ya que de diversas maneras nos representamos como seres vivos, construimos nuestra visión de vida y mundo, y conjugamos el 
Memorias del VII Encuentro Nacional de Experiencias en la Enseñanza de la Biología y la Educación Ambiental y II Congreso Nacional de Investigación en la Enseñanza de la Biología

mundo con la vida y viceversa, para comprendernos y saber quiénes somos en el mismo.

Por eso, la educación desde la biología para este caso, debe ser una educación que nos permita relatar nuestros sentires sobre la vida y lo vivo desde la narrativa como una orientación didáctica, para volver a conectarnos con ella como seres vivos, para ser mejores seres sociales y humanos. Desde estas apreciaciones, la enseñanza de la vida desde la biología debe adecuarse a los contextos propios de trabajo, a la población, adaptando los estándares a las situaciones y procesos escolares, pero ante todo, debe permitir que el sujeto se relate, se narre, se identifique, se dignifique, se sienta animal, se sienta biológico, y restablezca sus vínculos invisibles pero no perdidos con la vida y lo vivo, desde la narración propia de su mundo de la vida.

Cuando el sujeto, a través de su identidad narrativa, se reconozca como ser biológico y animal, podrá reconocer el sentido de la vida misma y de lo vivo, como base fundante de lo que es, de quien es, como proveniente de un largo proceso evolutivo y temporal. Ese reconocimiento propio, desde sus relatos y narraciones, le permite verse y pensarse para llegar a un constructo social humano más justo, más equitativo, menos consumista, menos violento, menos miserable, más digno, no solo con el mismo, sino con el otro como si mismo y con el planeta del que proviene como ser vivo. Aquí es donde las narrativas de vida y vivo entran a robustecer los marcos de trabajo teóricos, epistemológicos, ontológicos y metodológicos, ya que no solo somos biología, somos bios, somos relatos de vida vivos, del vivir y comprendernos en este mundo, desde nuestra subjetividad, apoyándonos de los elementos propios de la labor educativa, de los propias exigencias laborales, educativas y administrativas, pero haciendo frente a otras maneras en las que se puede re significar el sujeto, la ciencia, la enseñanza de la biología y la sociedad.

Sin limitarnos a ser transmisores de una ciencia occidental que si bien ha establecido criterios, parámetros y teorías para ser abordada, desde el objeto de estudio, también ha perpetuado una única verdad, que se contextualiza en los textos escolares, sin acercar esa verdad estipulada a las realidades y mundos de vida de los jóvenes trapecistas. Somos en fin biología, y todo lo que nos rodea es biología. El sentido de ella está en cómo la enseñamos, a quien la enseñamos, la didáctica con la que mediamos nuestro quehacer educativo, los argumentos que planteamos desde nuestro discurso pedagógico, la puesta en escena de nuestro acto pedagógico, el sentido de hacer, ser, y enseñar biología en contexto, para un mundo real contemporáneo, que no solo es competitividad, individualismo y consumismo. Un mundo de la vida que debe aterrizarse a las poblaciones con las que trabajamos, al ahora. Es una tarea de reconocimiento continuo, de los mundos de vida, que tienen mucho que decir, recuperando la voz propia de los 
Memorias del VII Encuentro Nacional de Experiencias en la Enseñanza de la Biología y la Educación Ambiental y II Congreso Nacional de Investigación en la Enseñanza de la Biología

sujetos al ser y sentirse participes, al ver que sus propias realidades, como es el caso de los jóvenes trapecistas, los inhibe, los calla, los rechaza, los marca, los segrega, los olvida.

Es comprender la vida y lo vivo, sin limitarnos a los conceptos y contenidos, pero tampoco sin relativizar todo conocimiento sobre ello. No es enmarcarlo todo en un solo punto de vista positivista, objetivo y científico. Tampoco es inhibir el valor de todo conocimiento científico. Es más bien, una propuesta, una orientación didáctica para re significar las maneras de ver la vida y lo vivo desde la biología, siendo las narrativas de los mundos de vida, una opción pedagógica y alternativa a la esperada académicamente, una orientación didáctica que reconoce, que apropia, que accede a que la vida se refleje en un texto, un texto que apropia el lector, que lo siente como suyo, que lo vive, lo relata y le permite ser y transformar.

\section{Conclusiones}

Los jóvenes trapecistas se evidenciaron, como seres particulares, con sentires y pensares únicos, que, desde la motivación, el encuentro y el acompañamiento, accedieron a expresar sus relatos escritos y orales en torno a la vida y lo vivo; expresándose desde sus realidades y contextos particulares, desde sus mundos de vida y sus maneras de ser, vivir y actuar. Es por ello que, el quehacer educativo debe retomar el contexto de trabajo y práctica pedagógica propia, ya que, por las mismas disposiciones, a veces administrativas, a veces pedagógicas, a veces impositivas, y sin autonomía docente, se reproducen sin sentido, los contenidos curriculares y las conceptualizaciones desarraigadas e impropias, de modelos externos, que definitivamente desconocen las realidades particulares. Allí, la educación pierde su impacto ya que lo que se enseña se transmite desde los textos, los planteamientos y las teorías planteadas por la ciencia occidental, pero no se evidencia aprendizaje verdadero que oriente al sujeto a su propia transformación.

La construcción y comprensión de las narrativas del mundo de la vida de los jóvenes trapecistas, se consolidan como referentes históricos, temporales, contextuales y de vida cotidiana que pueden permear las maneras en que se construye conocimiento. Es así que se evidencia la posibilidad real de hacer de las narrativas y de la narrativa como un tipo de investigación cualitativa, una orientación didáctica para la enseñanza del concepto vida desde la biología en contexto.

La subjetividad, la intersubjetividad y el mundo de la vida son propios de las emociones, los sentimientos, las acciones. Pero a pesar de ser propias, en los contextos donde los jóvenes trapecistas han vivido y convivido, sus experiencias de vida son tachadas, recriminadas, desvaloradas, olvidadas. Casi que es como si 
Memorias del VII Encuentro Nacional de Experiencias en la Enseñanza de la Biología y la Educación Ambiental y II Congreso Nacional de Investigación en la Enseñanza de la Biología

no existieran o tuvieran la posibilidad como sujetos de reconocerse, de reflexionarse, de verse a sí mismos, en su propia identidad narrativa, en el espejo de su vida. Es por ello que la narrativa toma voz propia no solo como marco metodológico; también como manera de narrarse, de sentirse valorados como parte de un mundo y de unas condiciones de vida particulares, pero que a través de su propio ser vivo y ser narrativo, pueden plasmar en sus propios mundos para construir sus identidades.

Dentro de los contenidos curriculares y los planes de estudio, existe una presión contundente por transmitir y cumplir sin cesar, conceptos, estándares y logros. Para el caso de la vida y lo vivo, desde la enseñanza y el aprendizaje de la biología, se plantean, desde los niveles de escolaridad, unos estándares de contenido que los educandos "deben saber y saber hacer", para ingresar a la vanguardia del mundo competitivo, individualista, consumista y globalizante, que habitamos. A su vez, se obvia, se olvida y se restringe la voz propia de los sujetos, en torno a lo que viven, sienten o saben respecto a la vida y lo vivo, limitándose a la agrupación, caracterización y fragmentación de los seres vivos, de la vida y de la naturaleza. Sin desconocer las raíces de los múltiples estudios sobre los seres vivos, que han permitido conocerlos, estudiarlos, conservarlos, protegerlos, y ampliar la mirada sobre las características biológicas compartidas entre unos y otros, si es desde ya esencial, es este mundo contemporáneo y a la vez devastador de la propia vida y de los propios seres vivos, ahondar en la hipótesis de la biofilia, lo que permitiría desde la educación, que los sujetos se reconozcan como seres animales y biológicos que provienen de un proceso evolutivo; que son el resultado de millones de años de cambios no solo biológicos, también de cambios cognitivos y afectivos que le permitieron ser la especie humana que es, pero desde su origen hasta su descenso, en total conexión con la vida y con el planeta que vive.

Desde las narrativas de la vida y lo vivo, se evidencia una conexión de los jóvenes trapecistas con otros seres vivos, y con el propio planeta que habitan. Se reconocen como humanos que también comparten con otros seres vivos características biológicas básicas como nacer, crecer, reproducirse y morir. Es este pues, un punto de partida relevante para que las comprensiones de sus propios mundos de vida se liguen desde el proceso de enseñanza y aprendizaje.

Los mundos de vida de los jóvenes trapecistas son particulares en el sentido de la propia experiencia, como lo viene siendo para cualquier sujeto. Es una apuesta entonces para recuperar algo de la subjetividad latente que en la actualidad se reclama desde otras perspectivas filosóficas y humanas ya que está demostrado que la ciencia, a pesar de sus amplios aportes no es la única verdad, ni la única manera de apropiar el mundo para sí mismo. Es un medio mas no la totalidad del mundo que habitamos. 
Memorias del VII Encuentro Nacional de Experiencias en la Enseñanza de la Biología y la Educación Ambiental y II Congreso Nacional de Investigación en la Enseñanza de la Biología

La prefiguración, la configuración y la reconfiguración de las acciones humanas, se visualizan como dinámicas vivas, que hacen del sujeto un ser que imagina, que se ve reflejado en otras maneras de vivir, que retoma la ficción para hallar reflexiones y sentidos propios. A su vez se narra, se percibe, se entiende y plasma su vida real, desde su temporalidad, los símbolos y el lenguaje. Luego se lee desde el texto construido y decide sobre sí mismo, sobre su vida. Es allí cuando la triple mimesis, como imaginación narrada y creadora, permite hacer de la narrativa de los mundos de vida un acto poético, vivo y vital para ser en el mundo, en el aquí, en el ahora. Un medio de re significación del sí mismo, del sujeto y del mundo de la vida, en pro de que los jóvenes reflexionen y piensen críticamente sobre sus propias vidas y sus posibles transformaciones.

\section{Bibliografía}

- Barcena, F. (2000)., Mélich, J. (2000). Paul Ricoeur: Educación y narración. En: F. Barcena. La educación como acontecimiento ético. Natalidad, narración y hospitalidad. (pp. 91 - 124). Papeles de Pedagogía. Paidos Ediciones.

- Bolívar, A. (2002). ¿De nobis ipsis silemus?: Epistemología de la investigación biográfica - narrativa en educación. Revista Electrónica de Investigación Educativa.

- Buitrago, D., Zárate, S. (2007). La narración oral como estrategia metodológica en la enseñanza de las ciencias naturales (relaciones entre seres vivos) en niños de 9 a 11 años de edad. Tesis de pregrado. Licenciatura en Biología. Universidad Pedagógica Nacional. Bogotá, Colombia.

- Castaño, N., Leudo, M. (1998). Las nociones de los niños acerca de lo vivo. Implicaciones didácticas. Revista de la Facultad de Ciencia y Tecnología TEA (Col), núm. 4, pp. 49 - 57. Universidad Pedagógica Nacional. Bogotá, Colombia.

- Cerbino, M. (2004). La muerte y el vaciamiento del sentido de la vida. En M. Cerbino. Pandillas juveniles, cultura y conflicto de la calle (pp. 77-80). Editorial El Conejo. Quito, Ecuador.

- Diéguez, A. (2012). La búsqueda de una definición de vida. En A. Diéguez. La vida bajo escrutinio (p.p. 23-42). Ediciones de intervención cultural. España.

- Escámez, A. (2005). Enseñar biología hoy en los niveles obligatorios o el reto de una enseñanza motivadora para un aprendizaje significativo en los tiempos que corren. En: www.encuentros.uma.es. 
Memorias del VII Encuentro Nacional de Experiencias en la Enseñanza de la Biología y la Educación Ambiental y II Congreso Nacional de Investigación en la Enseñanza de la Biología

- Escudero, Haydeé B. Formas de experimentación contemporánea: representaciones de la vida/muerte, tensiones y desplazamientos. Universidad Nacional de la Patagonia San Juan Bosco. Universidad Nacional de la Plata. Argentina.

- Orjuela, L., Rivera, J. (2009). Ideas acerca de lo vivo que tienen los estudiantes de los grados primero y segundo de primaria de la Escuela Rural IED Verjón Alto (Choachí) y Escuela urbana IED Rafael Nuñez (Bogotá). Tesis de pregrado, Licenciatura en Biología. Universidad Pedagógica Nacional. Bogotá, Colombia.

- Páramo, P. (1999). Nuestros vínculos con los animales. Universidad Pedagógica Nacional. Facultad de Educación. Bogotá, Colombia.

- Perea, C. (2007). Definición y categorización de pandillas. Los casos de Colombia y México. Anexo II. Informe Colombia. Secretaría general de la nación de los estados americanos. Departamento de seguridad pública. Washington.

- Rengifo, C. (2005). Jóvenes, conflictos urbanos y alternativas de inclusión. Plataforma conflicto urbano y jóvenes. Colombia.

- Rivas, J., Herrera, D. (2009). Narración, conocimiento y realidad: un cambio de argumento en la investigación educativa. En J. Rivas. Voz y educación: La narrativa como enfoque de interpretación de la realidad (p.p. 5-31). Ediciones octaedro, S, L. Barcelona, España.

- Serrano, J.F., Sánchez, B. (2000). Concepciones de vida y muerte en jóvenes urbanos. Nómadas (Col), núm. 12, pp. 294 - 298. Fundación Universidad Central. Colciencias. Fundación para la promoción de la Investigación y la Tecnología del Banco de la República. Bogotá, Colombia.

- www.idipron.gov.co. (2012 - 2013). Modelo Pedagógico de Intervención. Misión. Instituto para la Protección de la Niñez y la Juventud. Bogotá, Colombia. 